\title{
Non-health outcomes affecting self-care behaviors and medical decision-making preference in patients with type 2 diabetes: a cross-sectional study
}

Ming-Jye Wang ${ }^{1,2^{*}}$ (D) Hung-Ming Lin ${ }^{3}$, Li-Chen Hung ${ }^{2,4}$ and Yi-Ting Lo ${ }^{5}$

\begin{abstract}
Background: The effects of patient sustained self-care behaviors on glycemic control are even greater than the effects of medical treatment, indicating the value of identifying the factors that influence self-care behaviors. To date, these factors have not been placed in a single model to clarify the critical path affecting self-care behaviors. The aims of this study were to explore the relationships of these factors and the differences in patient preference for medical decision-making.

Methods: A cross-sectional study was conducted among outpatients with type 2 diabetes at a regional teaching hospital. Purposive sampling was adopted to recruit 316 eligible patients via self-administered questionnaires. Partial least squares structural equation modeling was used for analysis.

Results: Significant direct pathways were identified from health literacy to self-efficacy, patient empowerment, and self-care behaviors; from self-efficacy to self-care behaviors; and from patient empowerment to self-care behaviors. Indirect pathways were from health literacy to self-care behaviors via self-efficacy or patient empowerment. The pathway from health literacy to self-efficacy was significantly stronger in those preferring shared decision-making than in those who preferred physician decision-making.

Conclusions: Health literacy is a critical factor in improving self-care behaviors in patients with type 2 diabetes, and the effect of health literacy on self-efficacy was more significant in the shared decision-making than in the physician decision-making. Therefore, developing an effective health strategy to strengthen health literacy awareness and designing friendly, diverse health literacy materials, and application tools is the most important factor to facilitate self-care behaviors in this population.
\end{abstract}

Keywords: Health literacy, Self-efficacy, Patient empowerment, Self-care behaviors, Type 2 diabetes

\footnotetext{
* Correspondence: jye9129@gmail.com

'Department of Secretariat, National Taiwan University Hospital Hsin-Chu Branch, No.25, Lane 442, Sec.1, Jingguo Rd, Hsinchu City 300, Taiwan

${ }^{2}$ Department of Healthcare Management, Yuanpei University of Medical Technology, Hsinchu, Taiwan

Full list of author information is available at the end of the article
}

C C The Author(s). 2020 Open Access This article is licensed under a Creative Commons Attribution 4.0 International License, which permits use, sharing, adaptation, distribution and reproduction in any medium or format, as long as you give appropriate credit to the original author(s) and the source, provide a link to the Creative Commons licence, and indicate if changes were made. The images or other third party material in this article are included in the article's Creative Commons licence, unless indicated otherwise in a credit line to the material. If material is not included in the article's Creative Commons licence and your intended use is not permitted by statutory regulation or exceeds the permitted use, you will need to obtain permission directly from the copyright holder. To view a copy of this licence, visit http://creativecommons.org/licenses/by/4.0/. The Creative Commons Public Domain Dedication waiver (http://creativecommons.org/publicdomain/zero/1.0/) applies to the data made available in this article, unless otherwise stated in a credit line to the data. 


\section{Background}

Diabetes is a life-long chronic condition that leads to serious consequences. Over 425 million people worldwide are currently living with diabetes [1], with 1.6 million deaths directly attributed to diabetes each year [2]. Therefore, the World Health Organization (WHO) calls on countries to prevent or delay the onset of diabetes by promoting a healthy lifestyle, to reduce the risk of diabetes and effectively manage the disease to decrease the rates of complications and mortality [3].

To effectively control the progression of diabetes, prevent long-term complications, and promote quality of life, patients with diabetes need effective self-care behaviors (SCB) [4], which have an even greater impact than medical treatment [5]. SCB refers to "decisions and actions that an individual can take to cope with a health problem or to improve his or her health" [6]; according to the American Association of Diabetes Educators (AADE) [7] defined the AADE 7 Self-Care Behaviors ${ }^{\text {TM }}$ that included healthy eating, being active, monitoring, taking medication, problem solving, healthy coping, and reducing risks. Effective self-care behaviors are necessary to maintaining optimal HbA1C levels [8], particularly in patients with type 2 diabetes (T2DM) $[9,10]$. In recent years, there has been a call for health care evaluations to move beyond the measurement of health outcomes, and to consider the value of non-health outcomes, such as empowerment, psychosocial outcomes, and quality of life [11]. Therefore, clarifying the impact of non-health outcomes on SCB is an urgent issue.

Health literacy (HL) is defined as "the degree to which individuals have the capacity to obtain, process, and understand basic health information and services needed to make appropriate health decisions" [12]. It is increasingly recognized as an important modifiable psychosocial factor in the self-management behaviors of patients with T2DM [13], and is also theorized to be an important non-clinical factor in decreasing the risk of adverse outcomes in diabetes [14]. HL is considered to be positively correlated with SCB $[13,15,16]$, and can also affect SCB via self-efficacy $[17,18]$. Therefore, HL is one of widely used in studying patient-related predictors of health behaviors [19].

Another factor well known to be associated with SCB in patients with diabetes is self-efficacy (SE), which is "the belief in one's capacity to organize and execute the courses of action required to manage a prospective situation" [20]. SE is the main factor that directly affects health behaviors [21]. Patients with high SE have better compliance with SCB [22], both general SE and diseasespecific SE can affect SCB [23]. To improve the SCB of patients with diabetes, high SE is necessary.

Diabetes self-management is a complex lifelong journey whose prerequisites for success are the patient's active and responsible participation in the process. However, adopting and sustaining self-management practices may not always be easy. Then, motivation is an important factor in self-management, especially intrinsic motivation is more important than extrinsic motivation [24]. Intrinsic motivation refers to "engaging in a behavior or an activity for its own sake and personal rewards". Extrinsic motivation refers to "performing a behavior or an activity to earn a reward or avoid punishment" [25]. Patient empowerment $(\mathrm{PE})$ is a process designed to facilitate self-directed behavior change [26]. Therefore, PE is also one of another widely researched determinant of healthy behaviors [19]. The WHO defines empowerment as "a process through which people gain greater control over decisions and actions affecting their health" [27], which demonstrates that PE "doesn't mean 'giving' people power. Rather it's about 'enabling' them to recognize and use their power" [27]. Chen et al. [28] have found out that the empowerment approach has positive impact on improving SE and SCB. Patients with different health literacy levels may respond differently to PE. The Health Empowerment Model [29] proposes that $\mathrm{PE}$ is deeply interwoven with HL to affect the health outcomes of patients. Findings of the interactions between PE and HL in terms of health outcomes in patients are not consistent [30].

As mentioned above, patients with diabetes require a high level of responsibility and promise to implement a new lifestyle of SCB. HL, SE, and PE have been reported to directly or indirectly affect SCB $[13,15,16,23,29]$, but they have not yet been integrated into a single model to identify their influence on SCB, including differences in patient preferences for medical decision-making. This study used partial least squares structural equation modeling (PLS-SEM) to analyze these relationships. The aims of the current study were to: 1 ) investigate the relationships between $\mathrm{HL}, \mathrm{SE}$, and $\mathrm{PE}$ on $\mathrm{SCB}$ in patients with T2DM; and 2) compare the differences in these relationships by preference in making medical decisions. These findings may provide a more effective reference to guide professional interventions, and improve SCB in patients with T2DM; thereby, helping these patients achieve effective blood glucose control and avoid complications associated with uncontrolled disease.

\section{Methods \\ Study participants}

The study was conducted with the participation of outpatients who were diagnosed with T2DM for more than 1 year (primary diagnosis included up to three diagnostic codes in the International Classification of Diseases, Ninth Revision, Clinical Modification: 250) upon visiting the Department of Metabolism of a regional teaching hospital in Hsinchu City, Taiwan. Purposive sampling 
was adopted to recruit eligible patients with consent during all clinic sessions from June through September 2017. Researchers described the purpose of this study briefly prior before acquiring written informed consent and distributing the questionnaires. A total of 372 questionnaires were distributed, and 316 completed selfadministered questionnaires were collected, for a rate of valid questionnaires of $85 \%$. The questionnaires include the scales of $\mathrm{HL}, \mathrm{SE}, \mathrm{PE}$, and $\mathrm{SCB}$, and the patient's preference in making medical decisions.

\section{Research scale design}

Data were derived from patients' self-administered questionnaires. The questionnaire for this study was developed with reference to pre-existing validated scales and was adapted to conditions in this region, including the medical environment and terms understandable for patients. They were reviewed by an expert panel whose members included a specialist physician, dietitian, and health educator. The items included in the scale were selected for applicability and ease of administration. The details of each scale are as follows.

The HL scale was developed with reference to the Functional Communicative and Critical Health Literacy (FCCHL) scale developed by Ishikawa et al. [31]. The scale consists of 14 items in three dimensions: functional health literacy (FHL), 5 items; interactive health literacy (IHL), 5 items; and critical health literacy (CHL), 4 items. Each item was scored on a 5-point Likert scale (from $1=$ strongly disagree to $5=$ strongly agree). Mean scores of HL were obtained by summing the 14 item scores and dividing by the number of items, with higher scores indicating higher HL.

The SE scale used in this study was developed based on the Diabetes Self-Efficacy Scale [32] and Perceived Diabetes Self-Management Scale [33], which included 19 items on a 5 -point Likert scale (from $1=$ strongly disagree to $5=$ strongly agree). Mean scores of SE were obtained by summing the 19 item scores and dividing by the number of items, with higher scores indicating higher SE.

The PE scale used in this study referred to the Chinese Diabetes Empowerment Process Scale [34], which included 15 items with 5 -point Likert scale (from $1=$ strongly disagree to $5=$ strongly agree). Mean scores of PE were obtained by summing the 15 item scores and dividing by the number of items, with higher scores indicating higher PE.

The SCB scale used in this study was developed with reference to the Diabetes Self-Management Questionnaire [35], containing 14 items on 5-point Likert scale (from $1=$ strongly disagree to $5=$ strongly agree). Mean scores of SCB were obtained by summing the 14 item scores and dividing by the number of items, with higher scores indicating higher SCB.

The patient's preference decision scale was based on the Patient's Role Preference in Decision-Making questionnaire [36]. Patients selected their preference for making medical decisions, selecting one of these five items: $1=$ like to make treatment decisions on their own; $2=$ like to make treatment decisions on their own after listening to physician's opinion; $3=$ like to make treatment decisions together with the physician; $4=$ like physician to make treatment decisions after talking to the patient; and $5=$ like physician to make treatment decisions alone. Upon analysis, patients were categorized into three groups: patient decision-making (answers 1 and 2), shared decision making (SDM) (answer 3), and physician decision-making (answers 4 and 5).

\section{Data analysis}

The PLS-SEM incorporates into canonical correlation concepts the important statistical analysis techniques of regression analysis, principal component analysis, and path analysis. PLS-SEM can be applied to Mediation and Moderation analysis, and has gained universal attention in the field of health care [37]. It can not only help the researcher handle measurement problems of variable reduction but also addresses the structural problems of predicting and interpreting relationships in the research hypothesis. In interpreting the relationship of the latent variable to the dependent variable in regression analysis, this type of analysis is not affected by multi-collinearity, being distribution-free, requires only a small sample size, and can be applied to either formative or reflective measurements [38]. PLS-SEM was used to investigate the relationships between $\mathrm{HL}, \mathrm{SE}$, and $\mathrm{PE}$ on SCB in patients with T2DM. The patient's preferences in decisionmaking primarily included SDM and physical decisionmaking, in order to test the effects of moderation on differences in preference for medical decision-making, a multi-group analysis was conducted by comparing differences in coefficients of the corresponding structural paths for the constructs. A $p$-value of 0.05 or lower indicated a significant difference between groups. Descriptive statistics, including mean, standard deviations, and frequency, were used to analyze the distribution of patient characteristics, HL, SE, PE, SCB, and decision preferences. SmartPLS 3.0 (Institute of Operations Management and Organizations, University of Hamburg, Germany) was used for data analysis.

\section{Results}

\section{Study participant characteristics}

Among the 316 valid self-administered questionnaires, $39.6 \%$ were male and $60.4 \%$ were female. Those aged $\geq 65$ years accounted for $63.3 \%$ of the study population; 
Table 1 Participant's characteristics

\begin{tabular}{lcclcc}
\hline & $N$ & $\%$ & & N & $\%$ \\
\hline Sex & & \multicolumn{4}{l}{ Patient's preference decision } \\
Male & 125 & 39.6 & SDM & 138 & 43.7 \\
Female & 191 & 60.4 & Physician decision & 178 & 56.3 \\
Age & & & Educational \\
$\leqq 54$ & 45 & 14.2 & Elementary school & 136 & 44.7 \\
$55-64$ & 71 & 22.5 & Middle school & 54 & 17.8 \\
$65-74$ & 103 & 32.6 & High school & 67 & 22.0 \\
$\geqq 75$ & 97 & 30.7 & College or high & 47 & 15.5 \\
\hline N number of participants; SDM shared decision making &
\end{tabular}

44.7\% had an elementary school education and 22.0\% had a high school education. In terms of decisionmaking preferences, $56.3 \%$ preferred physician decisionmaking and $43.7 \%$ preferred SDM (Table 1).

\section{Reliability and validity}

In this study results were analyzed by measurement mode. Three criteria, including internal consistency, indicator reliability, and average variance extracted (AVE), were used to assess the convergent validity of each construct. The factor loadings of each dimension were between 0.592 and 0.939 (Fig. 1). The factor loading of FHL was 0.339. According to Hair et al. [39], the factor loading of each dimension is recommended to be $\geq 0.5$, so the FHL dimension was excluded from measurement mode analysis. Table 2 shows the Cronbach's $\alpha$ and Composite Reliability (CR) values of each scale were greater than 0.7 , which indicated good construct reliability and high internal consistency [40, 41]. The AVE was greater than 0.5, showing convergent validity [42]. Fornell and Larcker's test shows that the correlation coefficient was lower than the value of the diagonal element ( $\sqrt{\mathrm{AVE}})$, indicating that the measurement mode had the required discriminant validity [43].

The scales were scored on 5-point Likert scale, with average values ranging from 3.42 to 4.03 , indicating that participants had a more positive attitude towards each scale, especially PE (Table 2).

\section{Relationships between health literacy, self-efficacy, and patient empowerment on self-care behaviors}

To clarify the path of HL, SE, and PE on SCB, this study applied the PLS Bootstrap method with 5000 resamplings to obtain inference statistics. As shown in Table 3, HL had a direct positive effect on SE (path coefficient 0.516, $\mathrm{t}$ value $=8.755, p<0.001$ ), PE (path coefficient 0.450, $\mathrm{t}$ value $=9.749, \mathrm{p}<0.001$ ), and SCB (path coefficient $0.197, \mathrm{t}$ value $=3.705, \mathrm{p}<0.001)$. SE had a direct positive effect on $\mathrm{SCB}$ (path coefficient 0.433, t value $=6.526, \mathrm{p}<0.001$ ) and PE had a direct positive effect on SCB (path coefficient $0.174, \quad \mathrm{t}$ value $=2.890, \quad p<0.01)$. HL also indirectly

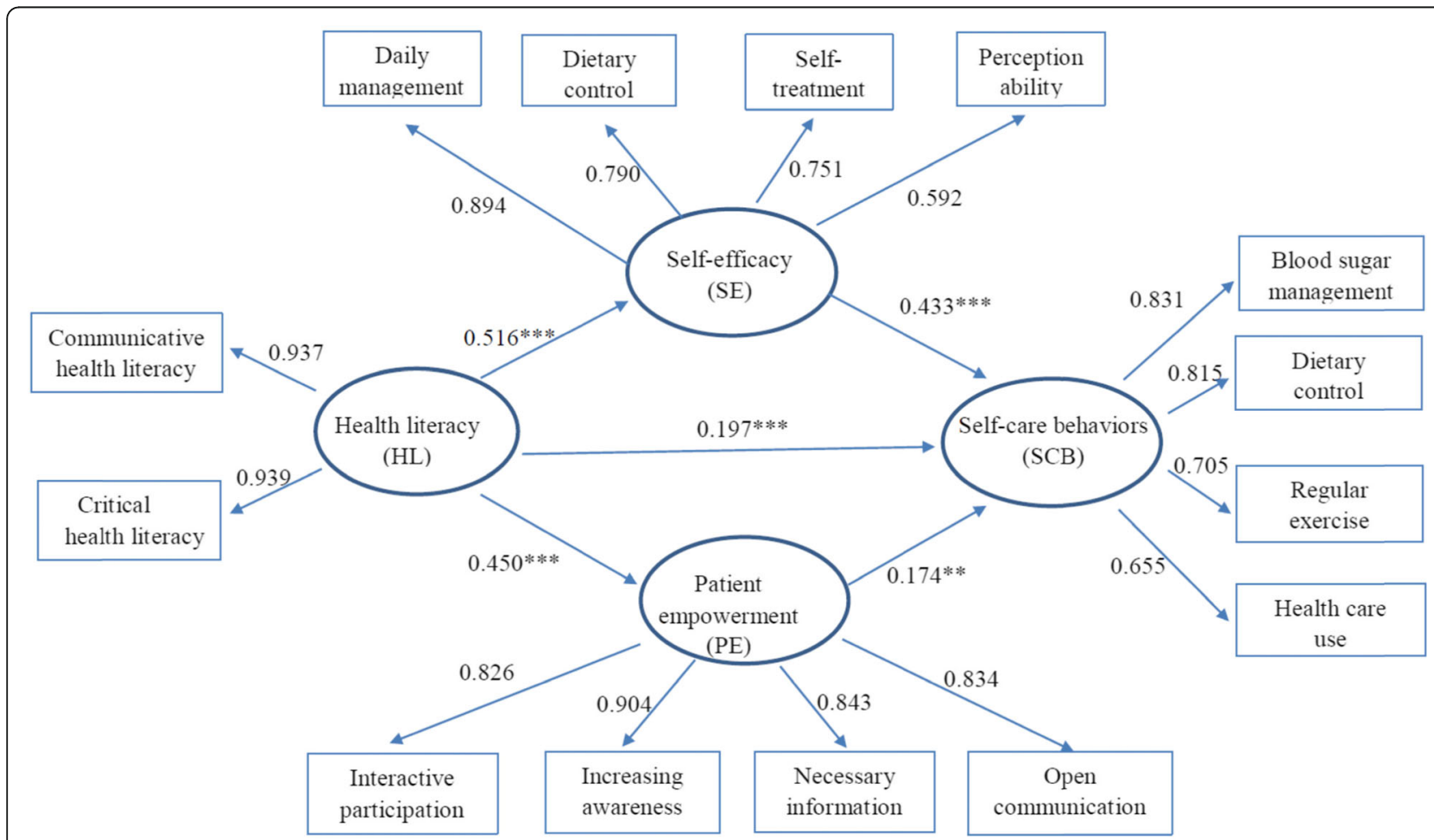

Fig. 1 Path model of health literacy $(\mathrm{HL})$, self-efficacy $(\mathrm{SE})$, and patient empowerment (PE) on self-care behaviors $(\mathrm{SCB}) .{ }^{* *} P<0.01 ;{ }^{* * *} P<0.001$ 
Table 2 Reliability, convergent, and discriminant validity of measurement model

\begin{tabular}{|c|c|c|c|c|c|c|c|c|c|}
\hline \multirow[t]{2}{*}{ Construct } & \multirow[t]{2}{*}{ Mean } & \multirow[t]{2}{*}{ SD } & \multicolumn{4}{|c|}{ correlation } & \multirow{2}{*}{$\begin{array}{l}\text { Cronbach's } \\
\text { a }\end{array}$} & \multirow[t]{2}{*}{$C R$} & \multirow[t]{2}{*}{ AVE } \\
\hline & & & $\mathrm{HL}$ & SE & $P E$ & $S C B$ & & & \\
\hline $\mathrm{HL}$ & 3.42 & 0.47 & 0.938 & & & & 0.863 & 0.936 & 0.880 \\
\hline SE & 3.82 & 0.47 & 0.516 & 0.764 & & & 0.754 & 0.846 & 0.584 \\
\hline PE & 4.03 & 0.48 & 0.450 & 0.638 & 0.853 & & 0.876 & 0.914 & 0.727 \\
\hline SCB & 3.66 & 0.52 & 0.499 & 0.646 & 0.539 & 0.755 & 0.762 & 0.840 & 0.570 \\
\hline
\end{tabular}

SD standard deviation; $H L$ health literacy; SE self-efficacy; PE patient empowerment; SCB self-care behaviors; $C R$ composite reliability; AVE Average variance extracted

influenced SCB via SE and PE (for SE: path coefficient 0.223 , $\mathrm{t}$ value $=4.766, \mathrm{p}<0.001$; for $\mathrm{PE}$ : path coefficient $0.079, \mathrm{t}$ value $=2.890, \mathrm{p}<0.01)$. The relationships are shown in Fig. 1.

\section{Comparing differences in relationships by preference in medical decision-making}

To compare the relationships differences in terms of preference decisions (SDM and physician decision), Hensler et al. [44] pointed out that Measurement Invariance Assessment is necessary, which includes three steps: configural invariance, compositional invariance, and the equality of composite mean values and variances. Using the Measurement Invariance Assessment in SmartPLS usually automatically establishes configural invariance (Step 1). Table 4 shows the correlation coefficient of Step 2. In Step 3, the $p$ value of both the mean value and the variance were greater than 0.05 , which is not significant. These results show that the measurement invariance was established for the scales when measuring different groups.

In order to test the effects of moderation on preference in medical decision-making differences (SDM and physician decision), a partial least square multi-group analysis was conducted by comparing differences in coefficients of the corresponding structural paths for the constructs. $P$ values of 0.05 or lower indicated that there were significant differences between the paths in the

Table 3 Direct and indirect effects

\begin{tabular}{llll}
\hline Path & Path coefficient & t value & $P$ value \\
\hline Direct effect & & & \\
$H L \rightarrow S E$ & 0.516 & 8.755 & $0.000^{* * *}$ \\
$H L \rightarrow P E$ & 0.450 & 9.749 & $0.000^{* * *}$ \\
$H L \rightarrow S C B$ & 0.197 & 3.705 & $0.000^{* * *}$ \\
$\mathrm{SE} \rightarrow \mathrm{SCB}$ & 0.433 & 6.526 & $0.000^{* * *}$ \\
$\mathrm{PE} \rightarrow \mathrm{SCB}$ & 0.174 & 2.890 & $0.004^{* *}$ \\
$\mathrm{Indirect}$ effect & & & \\
$\mathrm{HL} \rightarrow \mathrm{SE} \rightarrow \mathrm{SCB}$ & 0.223 & 4.766 & $0.000^{* * *}$ \\
$\mathrm{HL} \rightarrow \mathrm{PE} \rightarrow \mathrm{SCB}$ & 0.079 & 2.890 & $0.004^{* *}$ \\
\hline${ }^{* *} p<0.01 ;{ }^{* * *} p<0.001$ & & &
\end{tabular}

groups [45]. The results demonstrated that of the five paths, HL positively affecting SE was significantly stronger for the SDM group than for the physician decision group (Table 5, path coefficient $0.249, p<0.01$ ).

\section{Discussion}

This study is the first to place HL, SE, PE, and SCB in patients with T2DM in the same model to clarify their relationships using PLS-SEM, as well as to test the effect of $\mathrm{HL}$ on SE was more significant in the SDM group than in the physician decision-making group.

These findings clarify the relationships of $\mathrm{HL}, \mathrm{SE}$, and $\mathrm{PE}$ to $\mathrm{SCB}$, which are: HL directly positively influences SE and SCB, and SE directly positively influences SCB. $\mathrm{HL}$ can also indirectly influence SCB through SE. These relationships were consistent with previous researches $[8,17,18]$. Patients with higher HL can better promote their own health-related behaviors, and they may feel more confident in their ability to complete SCB [46, 47]. In particular, IHL and CHL have a greater impact on SE than FHL [8]. The more patients can enhance their SE, the more they may feel empowered to handle their situation [48], so HL plays an important role in the impact of $\mathrm{SCB}$, and $\mathrm{SE}$ is also an important predictor of $\mathrm{SCB}$ [23].

This study also further clarified the effect of HL and $\mathrm{PE}$ on $\mathrm{SCB}$, which is: HL directly positively influences $\mathrm{PE}$, and PE directly positively influences SCB. HL can also indirectly influence SCB through PE. Studies have shown that HL and PE are deeply interwoven [22], and each independently affects SCB [49], but limited HL is a threat to PE and self-management [50]. Wang et al. [30] proposed that $\mathrm{PE}$ may promote $\mathrm{SCB}$ in patients with high IHL and CHL, but may have no effect on SCB in patients with low communicative and critical health literacy (CCHL). Obviously, no matter patients are empowered externally or internally, these empowerment may sustained only when patients have adequate HL. Increasing HL is an antecedent of PE [51-53]. Strengthening PE without adequate HL may lead patients to harm their health condition by making uninformed decisions, and $\mathrm{HL}$ plays a bigger role than $\mathrm{PE}$ in determining health status [19]. 
Table 4 Results of the measurement invariance assessment

\begin{tabular}{|c|c|c|c|c|c|c|}
\hline \multirow[t]{2}{*}{ Construct } & \multicolumn{2}{|l|}{ Step 2} & \multicolumn{4}{|l|}{ Step 3} \\
\hline & Correlation coefficient & $P$ value & Variance & $P$ value & Mean value & $P$ value \\
\hline$\overline{\mathrm{HL}}$ & 1.000 & 0.508 & 0.155 & 0.567 & 0.179 & 0.125 \\
\hline SE & 0.996 & 0.141 & 0.383 & 0.088 & -0.086 & 0.397 \\
\hline PE & 0.998 & 0.447 & 0.029 & 0.883 & -0.064 & 0.545 \\
\hline SCB & 0.997 & 0.508 & 0.160 & 0.578 & -0.069 & 0.520 \\
\hline
\end{tabular}

Non-Significance at $p$ value $>0.05$ show the measurement invariance was established

In this study, the mean PE was 4.03 and the mean SE was 3.82, indicating that patients tended to have high PE and SE. The combined care plans for patients with T2DM under the National Health Insurance System in Taiwan encourages patients to be empowered by health providers. Participating physicians, health educators, and dieticians must be certified to implement this plan in order to assist patients undergoing regular medical treatment and self-health management, and follow the patients' medical regimen. The components of the initial or continuing care visit include a medical history, physical examination, laboratory evaluation, management plan, and diabetes self-management education, so PE and SE are generally high. However, the mean of the HL scale was 3.42 , indicating that patients' HL was obviously insufficient, and the mean of the SCB scale (3.66) was not high as well. Although these patients had the beliefs and actions to perform health behaviors and wanted to control their own health behaviors, they still felt a strong sense of powerlessness. Therefore, the self-management behaviors of the patients relied too heavily on the health care system to take active responsibility for SCB. The mindset of these patients must be changed, and their self-improvement in HL is the cornerstone by which to promote SCB.

In terms of the differences in preference in decisionmaking (SDM vs physician decision), HL directly positively affected SE in the five paths of Fig. 1 significantly more for the SDM group than for the physician decision group. Because HL can improve the ability of the patient to perform SCB, the patient then is better able to participate in SDM [54], further influencing clinical decisions. Patients will be more confident to take on self- management when they have more health-related knowledge, feel they can seek out resources and applications, and have positive interactions with health care professionals. As a result, the self-efficacy of patients is also improved. The study by Brabers et al. [54] showed that HL was associated with patient involvement in SDM, especially CHL. Patients participating in SDM have an increased commitment to health behaviors [55] and greater awareness and confidence to start their treatment [56]. Also, because patients with HL are more likely to play an active role in clinical decision-making, patients with HL are much more likely to show behavioral change [57]. Because HL involves obtaining, processing, and understanding health information for all aspects of health care, such as prevention, screening, diagnosis, and treatment, it is considered the basis of the health care delivery system [58].

Limitations of this study include the fact that participant inclusion was based on patient consent, which may have introduced selection bias into the study sample. This study selected only a single regional hospital, which may be a limitation of extrapolation the data. Also, the sample included only outpatients with T2DM; those with other types of diabetes, severity, duration of diabetes, and morbidity or more advanced disease, may have different outcomes. SCB was evaluated using a questionnaire and was not measured objectively. Further study is needed to explore the specific factors that influence HL in order to improve the level of HL.

\section{Conclusions}

This study provides insight into HL as the most important factor in the facilitation of self-care behaviors in

Table 5 Multi-Group Analysis

\begin{tabular}{lll}
\hline Path & Path coefficient difference (SDM Group-physician decision Group) & $P$ value \\
\hline $\mathrm{HL} \rightarrow \mathrm{SE}$ & 0.249 & $0.008^{* *}$ \\
$\mathrm{HL} \rightarrow \mathrm{PE}$ & 0.144 & 0.061 \\
$\mathrm{HL} \rightarrow \mathrm{SCB}$ & 0.171 & 0.919 \\
$\mathrm{SE} \rightarrow \mathrm{SCB}$ & 0.012 & 0.453 \\
$\mathrm{PE} \rightarrow \mathrm{SCB}$ & 0.060 & 0.322 \\
\hline
\end{tabular}

SDM shared decision making. ${ }^{* *}$ Significance at $p$ value $<0.01$

Results for a one-sided test 
patients with T2DM, and clarified the relationships between HL, SE, and PE on SCB. HL was found to have a direct positive effect on SE, PE, and SCB. HL also had an indirectly positive influence in SCB through SE and PE. Separately, SE and PE each directly positively affected SCB. In the SDM group, HL directly positively affected SE significantly more strongly than in the physician decision group. Therefore, developing an effective health strategy to strengthen health literacy awareness and designing friendly, diverse health literacy materials and application tools is necessary. In addition, promoting SDM to improve health outcomes and reduce complications in patient with T2DM is also necessary.

\begin{abstract}
Abbreviations
WHO: World Health Organization; SCB: Self-care behaviors; HbA1C: Glycated Hemoglobin; T2DM: Type 2 diabetes; HL: Health literacy; SE: Self-efficacy; PE: Patient empowerment; PLS-SEM: Partial least squares structural equation modeling; FCCHL: Functional Communicative and Critical Health Literacy; FHL: Functional health literacy; IHL: Interactive health literacy; CHL: Critical health literacy; SDM: Shared decision making; CR: Composite Reliability; AVE: Average Variance Extracted; CCHL: Communicative and critical health literacy
\end{abstract}

\section{Acknowledgements}

The authors would like to thank the participants who agreed to selfadministered questionnaire.

\section{Authors' contributions}

MJW took the lead on the design of the study, the analysis of the data and the writing of the manuscript. HML conducted data analysis and data interpretation. LCH involved in the study design and assisted with analysis. YTL participated in the study design and the collection of data. All authors read and approved the final version of the manuscript.

\section{Funding}

This study was supported by grants from the National Taiwan University Hospital, Hsin-Chu Branch, (107-HCH038). The funders had no role in the study design, data collection, data analysis or interpretation of the results, or in the writing of the manuscript.

\section{Availability of data and materials}

The data was collected from the patient's self-administered questionnaire with patient consent during the current study. The datasets are not publicly available, but are accessible from the corresponding author on reasonable request.

\section{Ethics approval and consent to participate}

This study was approved by the review board of National Taiwan University Hospital Hsin-Chu Branch (IRB No.106-018-E). All involving participants were fully informed about the content of the study, and they had the right to withdraw from the study at any time. Written informed consent was obtained prior to the interviews. This study was conducted in accordance with the Declaration of Helsinki.

\section{Consent for publication}

Not applicable.

\section{Competing interests}

The authors declare they have no competing interests.

\section{Author details}

'Department of Secretariat, National Taiwan University Hospital Hsin-Chu Branch, No.25, Lane 442, Sec.1, Jingguo Rd, Hsinchu City 300, Taiwan. ${ }^{2}$ Department of Healthcare Management, Yuanpei University of Medical Technology, Hsinchu, Taiwan. ${ }^{3}$ Department of Business Administration, Minghsin University of Science and Technology, Hsinchu, Taiwan.
${ }^{4}$ Department of Public Health, China Medical University, Taichung, Taiwan. ${ }^{5}$ Department of Development and Planning, National Taiwan University Hospital Hsin-Chu Branch, Hsinchu, Taiwan.

Received: 8 January 2020 Accepted: 14 April 2020

Published online: 23 April 2020

\section{References}

1. Diabetes concerns every family [cited 2019 Mar. 24]. Available from: https:// www.idf.org/e-library/epidemiology-research/54-our-activities/455-worlddiabetes-day-2018-19.html.

2. 1.6 million death are directly attributed to diabetes each year [cited 2019 Mar. 24]. Available from: https://www.who.int/diabetes/en/.

3. World Health Day 2016: Beat diabetes [cited 2016 Jun 13]. Available from: http://www.who.int/campaigns/world-health-day/2016/en/.

4. American Diabetes Association. Standards of medical care in diabetes_2010. Diabetes Care. 2010;33:S11-61.

5. Anderson RM, Funnell MM, Aikens JE, Krein SL, Fitzgerald JT, Nwankwo R, et al. Evaluating the efficacy of an empowermentbased self-management consultant intervention: results of a twoyear randomized controlled trial. Ther Patient Educ. 2009;1:3-11

6. Self-Care Behavior [cited 2019 Oct 30]. Available from: https://www. encyclopedia.com/education/encyclopedias-almanacs-transcripts-andmaps/self-care-behavior.

7. AADE7 Self-Care Behaviors ${ }^{\oplus}$ [cited 2020 Mar 01]. Available from:https://www diabeteseducator.org/living-with-diabetes/aade7-self-care-behaviors.

8. Lee YJ, Shin SJ, Wang RH, Lin KD, Lee YL, Wang YH. Pathways of empowerment perceptions, health literacy, self-efficacy, and self-care behaviors to glycemic control in patients with type 2 diabetes mellitus. Patient Educ Couns. 2016;9(2):287-94.

9. Gao J, Wang J, Zheng P, Harrdorfer R, Kegler MC, Zhu Y, Fu H. Effects of selfcare, self-efficacy, social support on glycemic control in adults with type 2 diabetes. BMC Fam Pract. 2013;14:66-71.

10. Walker RJ, Gebregziabher M, Martin-Harris B, Egede LE. Relationships between social determinants of health and process and outcomes in adults with type 2 diabetes: validation of a conceptual framework. BMC Endocr Disord. 2014;14:82-91.

11. McAllister M, Dunn G, Payne K, Davies L, Todd C. Patient empowerment: the need to consider it as a measurable patient-reported outcome for chronic conditions. BMC Health Serv Res. 2012;12:157.

12. Nielsen-Bohlman L, Panzer AM, Kindig DA. Health Literacy: a prescription to end confusion. Washington (DC): Institute of Medicine of the National Academies; 2004

13. Bailey SC, Brega AG, Crutchfield TM, Lasy T, Herr H, Kaphingst K. et al., Update on health literacy and diabetes. Diabetes Educ. 2014;40:581-604.

14. Health Literacy: A prescription to end confusion. The National Academies Press; 2004

15. Brega AG, Ang A, Vega, et al. Mechanisms underlying the relationship between health literacy and glycemic control in American Indians and Alaska natives. Patient Educ Couns. 2012:88(1):61-8.

16. Al Sayah F, Majumdar SR, Egede LE, Johnson JA. Associations between health literacy and health outcomes in a predominantly low-income african american population with type 2 diabetes. J Health Commun. 2015;20(5): $581-8$.

17. Bohanny W, Wu SF, Liu CY, Yeh SH, Tsay SL, Wang TJ. Health literacy, selfefficacy, and self-care behaviors in patients with type 2 diabetes mellitus. J Am Assoc Nurse Pract. 2013;25(9):495-502.

18. Sarkar U, Fisher $L$, Schillinger D. Is self-efficacy associated with diabetes selfmanagement across race/ethnicity and health literacy? Diabetes Care. 2006; 29(4):823-9.

19. Náfrádi L, Nakamoto K, Csabai M, Papp-Zipernovszky O, Schulz PJ. An empirical test of the health empowerment model: does patient empowerment moderate the effect of health literacy on health status? Patient Educ Couns. 2018;101(3):511-7.

20. Bandura A. Self-efficacy in changing societies. New York, NY: Cambridge University; 1995

21. Bandura A. Health promotion by social cognitive means. Health Educ Behav. 2004;31(2):143-64.

22. Reisi M, Mostafavi F, Javadzade H, Mahaki B, Tavassoli E, Sharifirad G. Impact of health literacy, self-efficacy, and outcome expectations on adherence to 
self-care behaviors in Iranians with type 2 diabetes. Oman Med J. 2016;31(1): 52-9.

23. King DK, Glasgow RE, Toobert DJ, Strycker LA, Estabrooks PA, Osuna D, Faber AJ. Self-efficacy, problem solving, and social-environmental support are associated with diabetes self-management behaviors. Diabetes Care. 2010;33(4):751-3.

24. Ahola AJ, Groop PH. Barriers to self-management of diabetes. Diabet Med. 2013:30(4):413-20

25. Differences of Extrinsic and Intrinsic Motivation [cited 2020 Mar 06]. Available from: https://www.verywellmind.com/differences-betweenextrinsic-and-intrinsic-motivation- 2795384.

26. Anderson RM, Funnell MM. Patient empowerment: myths and misconceptions. Patient Educ Couns. 2010;79(3):277-82.

27. Patient empowerment and health care [cited 2019 Feb. 8]. Available from: https://www.ncbi.nlm.nih.gov/books/NBK144022/.

28. Chen MF, Wang RH, Lin KC, Hsu HY, Chen SW. Efficacy of an empowerment program for Taiwanese patients with type 2 diabetes: a randomized controlled trial. Appl Nurs Res. 2015;28(4):366-73

29. Schulz PJ, Nakamoto K. Health literacy and patient empowerment in health communication: the importance of separating conjoined twins. Patient Educ Couns. 2013;90:4-11.

30. Wang RH, Hsu HC, Lee YJ, Shin SJ, Lin KD, An LW. Patient empowerment interacts with health literacy to associate with subsequent self-management behaviors in patients with type 2 diabetes: a prospective study in Taiwan. Patient Educ Couns. 2016:99(10):1626-31.

31. Ishikawa H, Takeuchi T, Yano E. Measuring functional, communicative, and critical health literacy among diabetic patients. Diabetes Care. 2008;31(5): 874-9.

32. Rapley P, Passmore A, Phillips M. Review of the psychometric properties of the diabetes self-efficacy scale: Australian longitudinal study. Nurs Health Sci. 2003;5:289-97.

33. Wallston KA, Rothman RL, Cherrington A. Psychometric properties of the perceived diabetes self-management scale (PDSMS). J Behav Med. 2007;30: 395-401.

34. Chen MF, et al. Diabetes empowerment process scale: development and psychometric testing of the Chinese version. J Adv Nurs. 2011;67(1):204-14.

35. Schmitt A, Gahr A, Hermanns N, Kulzer B, Huber J, Haak T. The diabetes selfmanagement questionnaire (DSMQ): development and evaluation of an instrument to assess diabetes self-care activities associated with glycaemic control. Health Qual Life Outcomes. 2013;11:13.

36. Bruera E, Sweeney C, Calder K, Palmer L, Benisch-Tolley S. Patient preferences versus physician perceptions of treatment decisions in cancer care. $J$ Clin Oncol. 2001;19:2883-5.

37. Waddimba AC, Beckman HB, Mahoney TL, Burgess JF Jr. The moderating effect of job satisfaction on Physicians' motivation to adhere to financially incentivized clinical practice guidelines. Med Care Res Rev. 2017;74(2):14877.

38. Pirouz, D.M. An Overview of Partial Least Squares. 2006 [cited 2018 Feb. 26]. Available from: http://ssrn.com/abstract= 1631359

39. Hair JF Jr, Black WC, Babin BJ, Anderson RE. Multivariate data analysis. 7th ed. Upper Saddle River, NJ: Pearson Prentice Hall; 2009.

40. DeVellis RF. Scale Development: Theory and applications (applied social research methods series, Vol. 26). Newbury Park, CA: Sage Publications; 2011.

41. Gefen, D., Straub, D. and Boudreau, M. Structural Equation Modeling and Regression: Guidelines for Research Practice. Communications of the Association of Information Systems. 2000; 4(7).

42. Chin WW. The partial least squares approach to structural equation modeling. In G. A. Marcoulides (Ed.), modern methods for business research (pp. 295-336). Mahwah, NJ: Lawrence Erlbaum Associates; 1998.

43. Fornell C, Larcker DF. Evaluating structural equation models with unobservable variables and measurement error. J Mark Res. 1981;18:39-50.

44. Henseler J, Ringle CM, Sarstedt M. Testing measurement invariance of composites using partial least squares. Int Mark Rev. 2016;33(3):405-31.

45. Sarstedt M, Henseler J, Ringle CM. Multi-Group Analysis in Partial Least Squares (PLS) Path Modeling: Alternative Methods and Empirical Results. Adv Int Mark. 2011:22:195-218.

46. Hou SI. Health education theoretical concepts, effective strategies and Core competencies. Health Promot Pract. 2014;15(5):619-21.
47. Diviani N, Camerini AL, Reinholz D, Galfetti A, Schulz PJ. Health literacy, health empowerment and health information search in the field of MMR vaccination: a crosssectional study protocol. BMJ Open. 2012;2(6):e002162.

48. Jaensson M, Dahlberg K, Nilsson U, Stenberg E. The impact of self-efficacy and health literacy on outcome after bariatric surgery in Sweden: a protocol for a prospective longitudinal mixed-methods study. BMJ Open. 2019;9(5): 27272.

49. Camerini AL, Schulz PJ. Health literacy and patient empowerment: separating con-joined twins in the context of chronic low back pain. PLoS One. 2015;10:e0118032.

50. Abdullah A, Liew SM, Salim H, Ng CJ, Chinna K. Prevalence of limited health literacy among patients with type 2 diabetes mellitus: a systematic review. PLoS One. 2019;14(5):e0216402.

51. Porr C, Drummond J, Richter S. Health literacy as an empowerment tool for low-income mothers. Fam Community Health. 2006:29(4):328-35.

52. Castro EM, Van Regenmortel T, Vanhaecht K, Sermeus W, Van Hecke A. Patient empowerment, patient participation and patient-centeredness in hospital care: a concept analysis based on a literature review. Patient Educ Couns. 2016;99(12):1923-39.

53. van Dam HA, van der Horst F, van den Borne B, Ryckman $\mathrm{R}$, Crebolder $\mathrm{H}$. Provider- patient interaction in diabetes care: effects on patient self-care and outcomes. A systematic review. Patient Educ Couns. 2003;51(1):17-28.

54. Brabers AE, Rademakers JJ, Groenewegen PP, van Dijk L, de Jong JD. What role does health literacy play in patients' involvement in medical decisionmaking? PLoS One. 2017;12(3):e0173316.

55. AsadiJanati N, Vahdat S, Yazdan PA. Studying patient participation in controlling postoperative infection in orthognathic surgery in BouAli hospital, Tehran in 2012-2013. Med Sci J. 2014;24(3):189-93.

56. Ghiyasvandian S, Mousavizadeh SN, Dehghan Nayeri N, Haghani H. The effect of decision Aid's Pakage in selected treatment by patients with early stage breast Cancer and decision making outcomes. J Fasa Univ Med Sci. 2013;3(3):271-9.

57. Khosravi A, Ahmadzadeh K, Arastoopoor S, R. T. Health Literacy levels of diabetic patients referred to shiraz health centers and its effective factors. Health Inf Manage. 2015;12(2):194-205.

58. Torres RY, Marks R. Relationships among health literacy, knowledge about hormone therapy, self-efficacy, and decision-making among postmenopausal health. J Health Commun. 2009;14(1):43-55.

\section{Publisher's Note}

Springer Nature remains neutral with regard to jurisdictional claims in published maps and institutional affiliations.

Ready to submit your research? Choose BMC and benefit from:

- fast, convenient online submission

- thorough peer review by experienced researchers in your field

- rapid publication on acceptance

- support for research data, including large and complex data types

- gold Open Access which fosters wider collaboration and increased citations

- maximum visibility for your research: over $100 \mathrm{M}$ website views per year

At $\mathrm{BMC}$, research is always in progress.

Learn more biomedcentral.com/submissions 